\title{
Experimental Study on Dynamic Characteristics of Loess Landslide in Tian Shui Region
}

\author{
JIA Yajun ${ }^{1,2, a}$, CHEN Cunli ${ }^{2, b_{*}}$, ZHANG Huyuan ${ }^{3, c}$ and MA Li ${ }^{1, d}$, \\ ${ }^{1}$ Gansu Forestry Technological College ,Tianshui ,Gansu 741020, China; \\ ${ }^{2}$ Civil Engineering and Architecture Institute, Xi'an University of Technology , Xi'an 710048, China; \\ ${ }^{3}$ MOE Key Laboratory of Mechanics on Western Disaster and Environment Mechanics, Lanzhou \\ University, Lanzhou, 730000, China \\ a2051738839@qq.com, 'littlemuch722@sina.com, '418232135@qq.com, d416200570@qq.com, \\ *Corresponding author.
}

Keywords: Landslide, dynamic characteristics, damping ratio.

\begin{abstract}
Loess landslide has a wide range of influence, great harm and difficult to control. Background of Panan landslide in Gansu, by field investigation and sampling analysis of indoor dynamic test method, under the action of dynamic stress, the vibration times of $\mathrm{N}_{\mathrm{f}}$ less than or equal to 30 times failure, the possibility of liquefaction of saturated undisturbed loess under uniform pressure. There is no possibility of liquefaction under bias consolidation. Under uniform pressure, the possibility of liquefaction of saturated reconstituted loess under low stress, the possibility of liquefaction under high stress $\left(\sigma_{3}>100 \mathrm{kPa}\right.$ ) is small .
\end{abstract}

\section{Introduction}

Three axis test on the action of loess in the slope[1],determination of dynamic modulus of undisturbed and reconstituted loess,damping ratio and dynamic strength,dynamic pore pressure, the variation law of dynamic modulus and dynamic damping ratio with strain is provided[2]. Dynamic pore pressure model[3,4,5], dynamic strength curves and failure modes when dynamic strength index of $\mathrm{N}_{\mathrm{f}}$ equal10,20,30 and parameters $\mathrm{c}_{\mathrm{d}} 、 \varphi_{\mathrm{d}}$.

\section{Sample preparation and test plan}

\subsection{Sample preparation}

The test soil sample includes undisturbed and reconstituted loess, in the natural water content and saturation state into action three axis test. The dry density and water content of the reconstituted loess are the same as the original loess. For undisturbed soil samples, special sample cutting device, the cutting diameter is about $3.91 \mathrm{~cm}$, and the height of the undisturbed loess sample is $8 \mathrm{~cm}$, samples with vernier caliper on the amount, diameter.

For reconstituted soil samples, sample preparation by pressure sample method, sample size for the diameter of $3.91 \mathrm{~cm}$, high $8 \mathrm{~cm}[4,6]$, according to the requirements of dry density and the water content of the sample to calculate the required wet soil weight[5], layered compaction of five equal parts with special compression molding[6,11,12]. After each layer is compacted, the soil surface is planed, and the next layer is compacted so that the layer can be directly touched to ensure the homogeneity of the sample[7,8]. The error between the dry density of the prepared sample is not more than $0.02 \mathrm{~g} / \mathrm{cm}^{3}$ 。 The sample is saturated with the method of gas extraction and saturation[9].

\subsection{Consolidation stress conditions for test control}

For undisturbed loess and saturated undisturbed loess, consolidation three triaxial test stress ratio $\mathrm{K}_{\mathrm{c}}=\sigma_{1} \mathrm{c} / \sigma_{3 \mathrm{c}}$ were 1.0、2.0, for the remodeling of loess and saturated loess, $\mathrm{K}_{\mathrm{c}}=1.0[10]$, The ambient pressure $\sigma_{3 \mathrm{c}}$ is $100 、 200 、 300 \mathrm{kPa}$. 


\section{Results and analysis}

\subsection{Dynamic modulus and damping ratio}

After the sample is pressed or consolidated, close drain switch, the dynamic stress is applied to each sample step by step, 5 times of vibration, the dynamic stress and dynamic strain are collected by the computer. In the case of isotropic consolidation, the stress and strain of the peak to curve of $\sigma_{\mathrm{d}} \sim$ $\varepsilon_{\mathrm{d}}$; In the consolidated case, according to the elastic strain, and the peak stress were made the curve of $\sigma_{\mathrm{d}} \sim \varepsilon_{\mathrm{d}}$ 。 According to the relationship of sorting out the dynamic modulus when different $\varepsilon_{\mathrm{d}}$ to $\mathrm{E}_{\mathrm{d}}$ , made curve of $\mathrm{E}_{\mathrm{d}} \sim \varepsilon_{\mathrm{d}}$ and $1 / \mathrm{E}_{\mathrm{d}} \sim \varepsilon_{\mathrm{d}}$ (i.e. $\varepsilon_{\mathrm{d}} / \sigma_{\mathrm{d}} \sim \varepsilon_{\mathrm{d}}$ ) 。According to Fig $1 \sim 4$ the elastic strain to sort out the curve of $\sigma_{\mathrm{d}} \sim \varepsilon_{\mathrm{d}} 、 \mathrm{E}_{\mathrm{d}} \sim \varepsilon_{\mathrm{d}}$, Fig 5 is sorting out the elastic strain curve of $1 / \mathrm{E}_{\mathrm{d}} \sim \varepsilon_{\mathrm{d}}$.

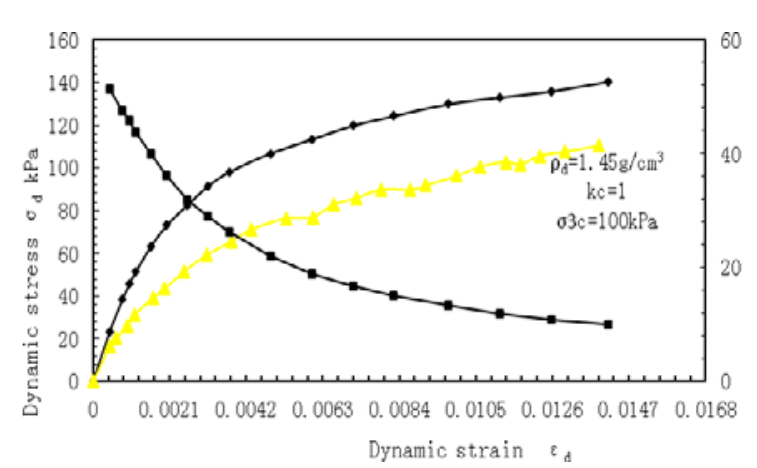

Fig. 1 Undisturbed loess curve of $\sigma_{\mathrm{d}} \sim \varepsilon_{\mathrm{d}} 、 \mathrm{E}_{\mathrm{d}} \sim \varepsilon_{\mathrm{d}}$

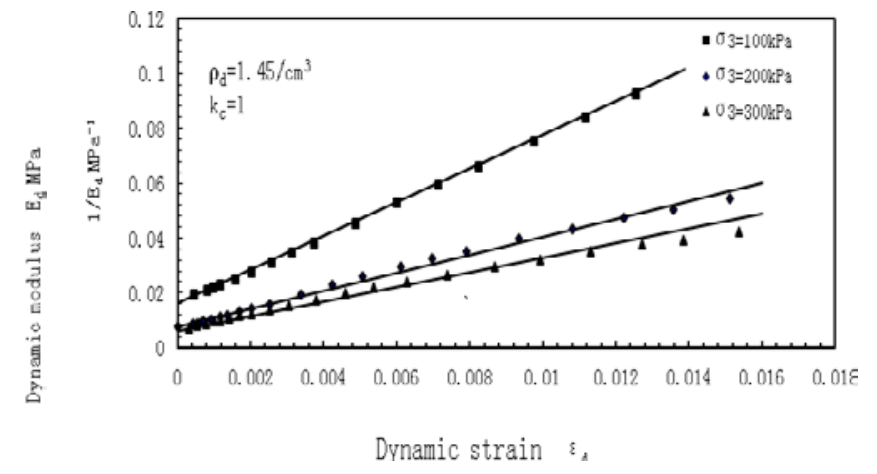

Fig. 2 Natural intact loess curve of $1 / E_{d} \sim \varepsilon_{d}$

From the test results can be seen, the relation of $\sigma_{\mathrm{d}} \sim \varepsilon_{\mathrm{d}}$ is similar to the hyperbolic relation, i.e.

$$
\sigma_{d}=\frac{\varepsilon_{d}}{a+b \varepsilon_{d}}
$$

In the formula a and $b$ are Test constant, so the relationship of $1 / E_{d} \sim \varepsilon_{d}$ is fitted to a straight line, a is in line with the longitudinal axis of the intercept, $b$ is slope of a straight line, and there is the following relationship:

$$
\mathrm{a}=1 / \mathrm{E}_{\operatorname{dmax}}, \mathrm{b}=1 / \sigma_{\text {dmax }}
$$

Determine a,b, $E_{d m a x}$ and $\sigma_{d m a x}$ under the different conditions on the results of the geotechnical test report 1 3。

And according to the dynamic modulus $E_{d}$ and shear modulus $G_{d}$ and relationship with compression strain $\varepsilon_{\mathrm{d}}$, shear strain $\mathrm{Y}_{\mathrm{d}}$ :

$$
G_{d}=\frac{E_{d}}{2(1+\mu)}
$$

$$
\gamma_{d}=(1+\mu) \varepsilon_{d}
$$

$\mathrm{G}_{\mathrm{d}} \sim \gamma_{\mathrm{d}}$ relationship curve was obtained ( for saturation and non saturation, $\mu=0.5$ 和 0.35 ).According to (3), (4) can be converted into the maximum shear modulus $\mathrm{G}_{\mathrm{dmax}}$, the maximum dynamic shear stress $\tau_{\mathrm{dmax}}$ and reference strain $\gamma_{\mathrm{r}}$ :

$$
\begin{gathered}
G_{d \max }=\frac{1}{2(1+\mu)} E_{d \max } \\
\tau_{d \max }=\frac{1}{2} \sigma_{d \max } \\
\gamma_{r}=\frac{\tau_{d \max }}{G_{d \max }}
\end{gathered}
$$

The damping ratio is calculated according to the dynamic stress and dynamic stress of each moment in a period of the selected vibration times $(\mathrm{N}=1)$, Then make $\lambda \sim \varepsilon_{\mathrm{d}}$ curve. (Fig.6) 

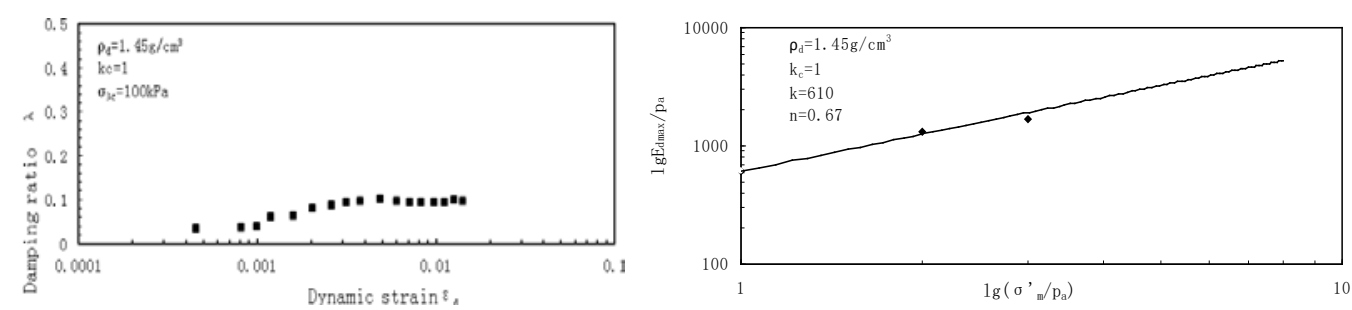

Fig. 3 Natural intact loess curve of $\lambda \sim \varepsilon_{d}$

Fig. 4 Natural intact loess curve of $1 g \mathrm{E}_{\mathrm{dmax}} / \mathrm{p}_{\mathrm{a}} \sim \lg \left(\sigma, \mathrm{m} / \mathrm{p}_{\mathrm{a}}\right)$

It is easy to see that although the damping ratio of the test point is a bit messy, but the damping ratio along with the dynamic strain of the change trend in line with the common law. Therefore, a test point fitting curve of $\lambda \sim \varepsilon_{\mathrm{d}}$, the curve forward, after extended by epsilon $\varepsilon_{\mathrm{d}}=10^{-4} \sim 10^{-2}$ range of different strain amplitude corresponding to the damping ratio.

3.2. Selection of calculation values of dynamic modulus and dynamic damping ratio

(1) Dynamic modulus

According to the results of dynamic three axis test (results of geotechnical tests are reported, which can be made in the double logarithmic coordinate system curve of $\mathrm{E}_{\mathrm{dmax}} / \mathrm{p}_{0}$ and $\sigma_{m}^{\prime} / \mathrm{p}_{\mathrm{a}}$ ). Test results show that, $\mathrm{E}_{\mathrm{dmax}} / \mathrm{p}_{\mathrm{a}}$ and $\sigma_{m}^{\prime} / \mathrm{p}_{\mathrm{a}}$ in the double logarithmic coordinate system, a linear relationship is linear, expressed by the following power function:

For elastic strain $\quad E_{\mathrm{d} \max }=k p_{\mathrm{a}}\left(\sigma_{m}^{\prime} / p_{\mathrm{a}}\right)^{n}$

In the formula $\mathrm{k}, \mathrm{n}$ as test parameters, $\mathrm{k}$ is intercept of $\sigma_{m}^{\prime} / \mathrm{p}_{\mathrm{a}}=1, \mathrm{n}$ is Slope of a straight line.Can use different test conditions of $\mathrm{k}, \mathrm{n}$, calculated the actual $\sigma_{m}^{\prime}$ corresponding $\mathrm{E}_{\text {dmax }}$.

Based on the results, press the three axis of maximum shear modulus $G_{d m a x}$ and reference strain $\gamma_{r}$ respectively of different consolidation pressure are normalized the results in Figure 8.

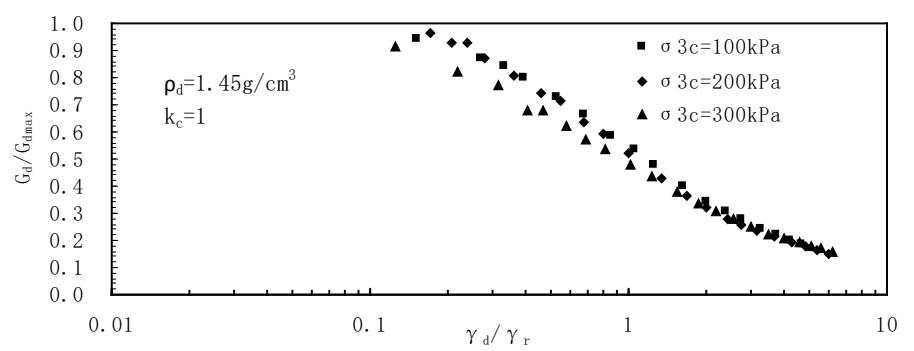

Fig. 5 Natural intact loess curve of $G_{d} / G_{d m a x} \sim \gamma_{d} / \gamma_{r}$

We can see that, at this time, the different consolidation pressure can be normalized curve better, the elastic strain has:

$$
\frac{G_{d}}{G_{d \max }}=\frac{1}{1+\frac{\gamma_{d}}{\gamma_{r}}}
$$

In the application, according to the corresponding strain range and the average effective principal stress, the results are reported in Table 1 from (8) or formula (9), calculate the corresponding maximum shear modulus $G_{d \max }$, and according to the corresponding strain range and the pressure size of the reference strain $\gamma_{\mathrm{r}}$, can get the corresponding dynamic shear modulus $\mathrm{G}_{\mathrm{d}}$.

(2) Damping ratio $\lambda$

The curves of $\lambda \sim \gamma_{\mathrm{d}}$ under different consolidation pressures are drawn on the same coordinate system, as shown in Figure 9. 


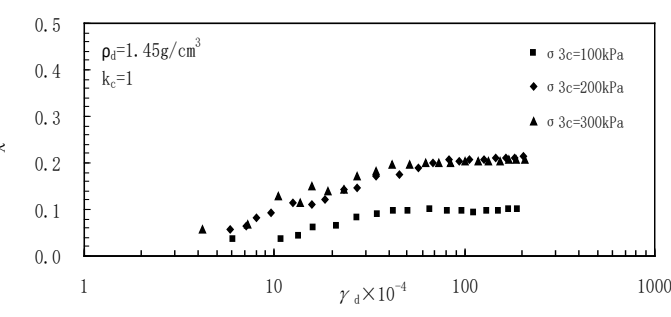

Fig. 6 Natural intact loess curve of $\lambda \sim \gamma_{d}$

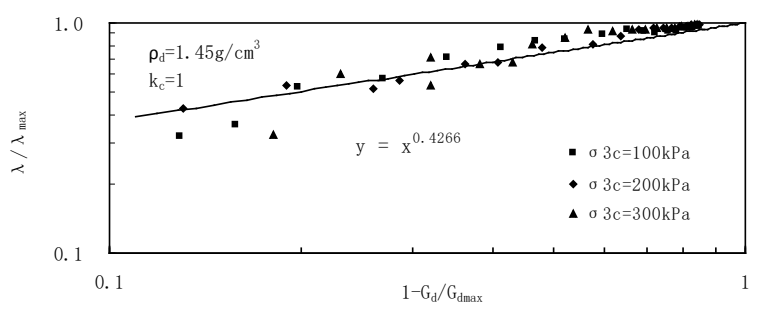

Fig. 7 Natural intact loess curve of $N / \lambda_{\max } \sim 1-G_{d} / G_{d \max }$

The results indicated that:

a. For the undisturbed loess, due to the influence of structure, the surrounding pressure of $\lambda \sim \gamma_{d}$ curve effect larger, $\lambda \sim \gamma_{d}$ curve with the surrounding pressure $\sigma_{3 c}$ increases and shift, namely under the same move strain $\gamma_{\mathrm{d}}$, damped $\lambda$ increases with the increase of the ambient pressure $\sigma_{3 \mathrm{c}}$, and the surrounding pressure $\left(\sigma_{3 c}=100 \mathrm{kPa}\right)$ is small, the effect larger, surrounding pressure $\left(\sigma_{3 \mathrm{c}} \geq 200 \mathrm{kPa}\right)$ is large, its influence is very small, the damping under different surrounding pressure ratio test point distribution in a relatively narrow range.

b. For unsaturated intact loess, due to the saturation the structural reduced significantly, ambient pressure to compaction and the surrounding pressure of $\lambda \sim \gamma_{d}$ curve effect larger, $\lambda \sim \gamma_{d}$ curve with the surrounding pressure $\sigma_{3 c}$ increases down, namely under the same move strain $\gamma_{d}$, damping ratio $\lambda$ decreases with the increase of the ambient pressure $\sigma_{3 c}$, and the ambient pressure $\left(\sigma_{3 c}=100 \mathrm{kPa}\right)$ is small, the effect of larger, surrounding pressure $\left(\sigma_{3 c} \geq 200 \mathrm{kPa}\right)$ is large, its influence is very small, under different surrounding pressure damping ratio test point distribution in a relatively narrow range.

c. The remolded loess, remoulded specimens also have certain structural and $\lambda \sim \gamma_{d}$ curve with the surrounding pressure $\sigma_{3 c}$ increases and the shift, namely under the same move strain $\gamma_{d}$, damping ratio $\lambda$ increases with the increase of the ambient pressure $\sigma_{3 c}$, but compared with the undisturbed loess, ambient pressure has little effect.

d. For the saturated remolded loess, due to remodeling and saturation to the structural disappeared in normal consolidation state, the surrounding pressure of $\lambda \sim \gamma_{\mathrm{d}}$ relationship curve, the impact is very small, the damping under different surrounding pressure ratio test point distribution in a relatively narrow range.

Above visible, in addition to saturated remolded loess under different experimental conditions, all need to consider the influence of confining pressure on damping ratio.

Draw the relationship between the $\left(\frac{\lambda}{\lambda_{\max }}\right)$ and $\left(1-\frac{G_{d}}{G_{d \max }}\right)$ (the experiment result $\lambda_{\max }$ is extended to the $\gamma_{\mathrm{d}}=2 \times 10^{-2}$, such as geotechnical test results table 2, 3) , as shown in Figure 10.

Above visible, under different ambient pressure, the test point in the double logarithmic coordinate system is more concentrated and can be approximated to a straight line, the linear equation is:

$$
\begin{aligned}
\lg \left(\frac{\lambda}{\lambda_{\max }}\right) & =\lg \left(1-\frac{G_{d}}{G_{d \max }}\right)^{m} \\
\text { And } \quad \frac{\lambda}{\lambda_{\max }} & =\left(1-\frac{G_{d}}{G_{d \max }}\right)^{m}
\end{aligned}
$$

Because the pressure around the same time and other conditions, the different pressure around the corresponding $\lambda_{\max }$ in a large difference, so the pressure around the different to take a $\lambda_{\max }$. test results $\mathrm{m}$ in report of Table $6 \sim 7$ under different conditions.

\section{Conclusion}

(1) The dynamic shear modulus of $G_{d}$ can be determined according to the formula (9) in different test conditions, and the $G_{\mathrm{dmax}}$ can be calculated by formula (8), and the $\gamma_{\mathrm{r}}$ is selected by the soil test result report in table $1 \sim 3$.

(2) Damping ratio by the soil test results report in table 4, 5, but also by the soil test results report 
in table 4 gives the formula to determine, different surrounding pressure respectively $\lambda_{\max }$ (see soil test results report in Table 6, 7).

(3) For different failure criterion $\left(\varepsilon_{\mathrm{df}}=2 \%, 5 \%\right), \mathrm{N}_{\mathrm{f}}=10,20,30$ times, dynamic shear strength index of $c_{d} 、 \varphi_{d}$ can be selected according to soil test results.

(4) In dynamic force, the destruction of the vibration times $\mathrm{N}_{\mathrm{f}}$ is less than or equal to 30 damage and saturated intact loess in equalizing the likelihood of liquefaction under consolidation, under anisotropic consolidation condition without the likelihood of liquefaction. Under the condition of uniform pressure consolidation,saturated remodeling loess has the possibility of liquefaction under low stress ( $\sigma_{3} \leq 100 \mathrm{kPa}$ ), and the possibility of liquefaction under high stress ( $\left.\sigma_{3}>100 \mathrm{kPa}\right)$ is very small.

\section{Acknowledgements}

Funded by Scientific research project of college in Gansu (2015A-188);The science and technology support program foundation of Tianshui (No. 2015-25)

\section{References}

[1] Olgun G, Martin J, Abdelaziz S, Iovino P, Catalbas F, Elks C, et al. Field testing of energy piles at Virginia Tech. In: Proceedings of the 37th annual conference on deep foundations, Houston, TX, USA; 2012.

[2] Biondi G, Cascone E, Maugeri M, et al. Seismic response of saturated cohesionless slopes [J]. Sarma SK. Seismic stability of earth dams and embankments [J]. Geotechnique, 1975, 25: 743-761.

[3] REINALDO V M, YONG S. Geogrid-reinforced and pile-supported roadway embankment[C]//Proceedings of Sessions of the Geo-frontiers 2005 Congress. Texas: The Geo-institute of the American Society of Civil Engineers,2005: 11-20.

[4] LIU Zu-dian. Mechanics and engineering of loess[M].Xi'an: Shannxi Science and Technology Press, 1997. (in Chinese).

[5] Moriwaki, H. (1993). “'Behaviour of pore-water pressure at slope failure.’’ Proc., 7th Int. Conf. and Field Workshop on Landslides, Czechand Slovak Republics, 263-268.

[6] Lumb, P. 1975. Slope failures in Hong Kong. Quarterly Journal of Engineering Geology, 8: 31-65.

[7] Han, K. K., and Rahardjo, H. (2000) “'Mechanism of rain-induced slope failures in residual soils," in “'Unsaturated Soils for Asia.” H. Rahardjo et al., eds., Proc., Asian Conf. on Unsaturated Soils (UNSATASIA 2000)—From Theory to Practice, Balkema, Singapore, 505-508.

[8] Lagioia, R., Puzrin, A. M. \& Potts, D. M. (1996). A new versatile expression for yield and plastic potential surfaces. Comput.Geotech. 19, No. 3, 171-191.

[9] Suryolelono, K.B., Natural Disaster Landslide Geotechnical Engineering Perspective, Inauguration Speech at the Faculty of Civil Engineering,Gadjah Mada University, Yogyakarta, 2003.

[10] Vanapilli, S.K, Fredlund D.G., Putahi D.E., dan Clifton A., Model for The Prediction of Shear Strength with Respect to Soil Suction Canadian Geotechnical journal 33:329-392,1996.

[11] JIA, Y. J., ZHANG,H. Y., et al. Experimental Study on Static Characteristics of Landslide Loess in Tianshui Region, J. Comput. Sci. Eng. 18 (2015) 610-613.

[12] JIA Ya-jun. Soil Mechanics and Foundation engineer[M].Xi'an: Xi'an Jiaotong university Press, 2014. (in Chinese). 